\title{
Steroid Diagnostics of 21st Century in the Light of Their New Roles and Analytical Tools
}

\author{
Michaela DUŠKOVÁ ${ }^{1,2}$, Lucie KOLÁTOROVÁ ${ }^{1}$, Markéta ŠIMKOVÁ ${ }^{1,3}$, \\ Monika ŠRÁMKOVÁ ${ }^{1}$, Mária MALÍKOVÁ ${ }^{2}$, Lenka HORÁČKOVÁ ${ }^{1,3}$, Jana VÍTKU' ${ }^{1}$, \\ Luboslav STÁRKA ${ }^{1}$
}

${ }^{1}$ Department of Steroids and Proteofactors, Institute of Endocrinology, Prague, Czech Republic,

${ }^{2}$ Department of Medicine Strahov, General University Hospital, Prague, Czech Republic,

${ }^{3}$ University of Chemistry and Technology, Prague, Czech Republic

Received March 21, 2020

Accepted April 20, 2020

\begin{abstract}
Summary
The determination of steroid hormones and subsequent interpretation of results is accompanied by a range of difficulties. The amount of information that current technology can provide on the circulating concentrations of more than a hundred various steroid compounds can lead to problems with interpretation. The aim of this study is to help provide orientation in this maze of data on steroid hormones. First we focus on specific aspects arising from the pre-analytical phase of steroid determination that need to be considered when planning sampling, whether for diagnostics or research. Then, we provide a brief summary of the characteristics and diagnostic relevance of several steroid hormones and/or their metabolites: pregnenolone, 17a-hydroxypregnenolone, dehydroepiandrosterone, hydroxyderivatives of dehydroepiandrosterone, androstenedione, testosterone, estrone, estradiol, estriol, cortisol, cortisone, which in our institute are determined with validated LC-MS/MS methods. For these steroids, we also provide newly calculated reference values in fertile women according to the phase of their menstrual cycle.
\end{abstract}

\section{Key words}

Pre-analytical phase - Estrogens - Age differences • Lesscommon steroids $\bullet$ LC-MS/MS

\section{Corresponding author}

M. Dušková, Institute of Endocrinology, Národní 8, 11694 Prague 1, Czech Republic. E-mail: mduskova@endo.cz

\section{Introduction}

In the early 50s, Zimmermann's reaction for the determination of 17-ketosteroids and the analysis of corticosteroids as 17-hydroxycorticosteroids or 17-ketogenic steroids in urine was the only way to obtain any information on steroid excretion. Since the 1970s, the discovery of immunologic analysis of hormones in the blood using Rosalyn Yellow opened the way for steroid analysis in fluids other than urine and allowed the determination of very small concentrations (pmol/1 of analytes). Immunoanalysis of individual steroids still prevails for diagnostic uses in clinical practice; however, sophisticated methods of tandem chromatography and mass spectrometry have found their place not only in steroid analysis for scientific purposes but also for the clinical diagnosis of various pathologies.

Instrumental analysis combining gas or liquid chromatography with mass spectrometry allows the simultaneous measurement of a large number of steroid metabolites, and has higher specificity than immunoanalytic methods. Measured values are therefore often somewhat lower than from immunoanalyses. The choice of method depends on the requirements for precision, economic factors, and the ability to incorporate automatization into routine analyses. Routine diagnostic examinations and other research uses also have different requirements. The range of information that current technologies deliver can often lead to data on more than 
a hundred circulating steroids, resulting in difficulties in interpretation. We know little about the roles of many hormones in various pathogenic disorders, and while we have certain information from experimental physiology, particularly for neuroactive steroids that act in the brain, we know almost nothing about their effects on health and disease. The aim of this work is to provide orientation into the maze of data on steroid hormones and their metabolites. We provide a brief summary of the characteristics and diagnostic relevance of several steroid hormones and/or their metabolites that in our institute are determined with validated liquid chromatography tandem mass spectrometry (LC-MS/MS) methods. For these steroids and methods, we also provide newly calculated reference ranges in fertile women (Table 1), which are in accordance with another study presenting reference ranges measured by LC-MS/MS as well (Eisenhofer et al. 2017). We do not include those steroids that we currently determine using conventional immunoassays, or the numerous steroids that can be determined using GC-MS/MS methods (Hill et al. 2019).

Table 1. Levels of selected steroids in fertile women in plasma.

\section{Fertile women steroids}

(age 25-35 years)

\section{Follicular phase Preovulation phase Ovulation phase Luteal phase}

\begin{tabular}{lcccc}
\hline Pregnenolone (nmol/l) & $0.39-6.83$ & $1.15-5.63$ & $1.61-13.47$ & $2.17-17.43$ \\
17-OH-pregnenolone (nmol/l) & $0.75-37.93$ & $1.42-46.36$ & $1.13-25.92$ & $1.13-28.42$ \\
DHEA (nmol/l) & $9.78-68.70$ & $14.12-86.05$ & $13.46-74.25$ & $10.79-71.13$ \\
$7 \alpha-O H-D H E A(n m o l / l)$ & $0.473-3.945$ & $0.605-3.879$ & $0.408-4.372$ & $0.641-3.353$ \\
$7 \beta$-OH-DHEA (nmol/l) & $0.175-1.528$ & $0.139-1.601$ & $0.240-1.847$ & $0.206-1.174$ \\
Androstenedione (nmol/l) & $1.36-5.97$ & $1.27-6.49$ & $1.72-8.31$ & $1.24-5.66$ \\
Testosterone (nmol/l) & $0.25-1.44$ & $0.34-1.58$ & $0.35-1.85$ & $0.28-1.85$ \\
Free testosterone (pmol/l) & $3.32-20.40$ & $5.5-22.3$ & $6.0-30.3$ & $3.19-26.60$ \\
Free testosterone (\% of total) & $0.63-2.45$ & $0.72-2.34$ & $0.65-2.26$ & $0.63-2.30$ \\
Bioavaliable testosterone (pmol/l) & $81.4-535$ & $147-567$ & $147-713$ & $78.4-694$ \\
Bioavaliable testosterone (\% of total) & $16.1-58.2$ & $18.1-55.3$ & $16.3-54.3$ & $15.1-54.7$ \\
Estron (nmol/l) & $0.054-0.451$ & $0.113-0.769$ & $0.190-1.032$ & $0.126-1.143$ \\
Estradiol (nmol/l) & $0.013-0.315$ & $0.067-0.808$ & $0.051-1.402$ & $0.088-0.848$ \\
Estriol (nmol/l) & LOD - 0.155 & LOD - 0.148 & LOD - 0.292 & LOD - 0.179 \\
Cortisol (nmol/l) & $205.0-714.6$ & $254.3-629.5$ & $298.2-684.7$ & $238.8-626.7$ \\
Cortisone (nmol/l) & $40.5-150.9$ & $43.6-96.1$ & $41.4-93.3$ & $45.5-93.3$ \\
\hline
\end{tabular}

Reference ranges were calculated based on the $2.5^{\text {th }}-97.5^{\text {th }}$ percentiles of measured data. Steroids were quantified using previously published LC-MS/MS method (Sosvorova et al. 2015, Vítků et al. 2016). SHBG (calculation of biological and free testosterone) was measured using radioimmunoanalytic kit from Immunotech (Beckman Coulter Company, Marseille, France). Albumin (calculation of biological and free testosterone) was determined using immunoanalytic assay from Roche (Basel, Switzerland). Biologically available testosterone was calculated according Vermeulen et al. (1999) http://www.issam.ch/freetesto.htm. For calculating reference ranges, 241 samples were analyzed from healthy women (average age 29.8 years, average BMI 24.56) that were not using any medications or hormonal contraceptives, had a regular menstrual cycle, and had no clinical signs of hyperandrogenemia. Dividing into four phases of the menstrual cycle was performed based on the day of the cycle and LH levels. All samples were taken in the morning hours between 7:30 and 9:30. LOD - detection limit.

\section{General comments}

Either serum or plasma may be used to determine steroid hormones. It has been mentioned that serum is more advantageous than plasma in light of the possible interference from small precipitates occurring in plasma during freezing and thawing. This possible interference is important mainly during measurements in small plasma volumes (0.05 ml) (Stanczyk 2006). In clinical practice the use of urine or saliva can also be useful, while determinations in other samples such as cerebrospinal fluid, seminal plasma, hair, or tissues are rather the subject of research.

Reference interval in the 2.5-97.5 percentile range is defined by concentration values of the given analyte in a defined population (i.e. a cohort of reference 
individuals defined as being healthy) (Racek et al. 2006). Each laboratory should determine reference values for the steroids they measure, as only such reference range enable a proper interpretation of results.

Steroid levels change physiologically with age (over years) as well as with reproductive function status (over months to years) and the menstrual cycle (over weeks), but also with seasonal and daily biorhythms. All these aspects cannot be captured in reference ranges, and therefore it is necessary to take the day of the menstrual cycle and time of day into account when determining reference norms. Physiological changes to steroid levels mean that different ranges are necessary for women and men, for different age groups, and for the menstrual cycle phase in women.

Steroidal compounds circulate in the blood or are excreted mainly in the urine as esters of sulfuric acid - sulfates, glucuronic - glucoronides or bound to other acids and lipids as so-called conjugates, or non-bound, non-conjugated, sometimes called somewhat imprecisely as "free". The term "free" is used in other contexts, and rather refers to steroid compounds circulating in the blood non-bound to proteins. These proteins have varying binding affinities, with specific globulins having the highest, for instance sex hormone binding globulin (SHBG) for $\mathrm{C}_{18}$ a $\mathrm{C}_{19}$ steroids with $17 \beta$-hydroxy-groups such as estradiol or testosterone, and cortisol binding globulin (CBG) for corticoids. Albumin has a low affinity for testosterone, while other proteins such as orosomucoid or CBG have higher. In light of the complex dynamics of steroids binding to proteins, plasma methods for determining free or biologically-active steroids are the subject of some criticism (Goldman et al. 2017).

\section{Searching for steroid functions}

The functions of the most common steroids in the human body have been well described. However, for less-common steroids this process is still underway. Steroids that were previously considered to be insignificant byproducts of metabolism or degradation products have become to be seen as important in physiology and in pathological states.

The search for further steroid functions involves complications arising from two basic sources of information. The literature contains descriptions of relationships between changes in steroid levels and certain diseases that come from experimental animal models. These results are often not applicable to humans, however, considering the differences in human steroidogenesis. Another source of information on relationships of steroids and pathologies are associative studies. These can be problematic in that the associations themselves do not show causation. However, they can be used to support new hypotheses, and are thus important. To understand the complicated relationships and functions of steroids, a fundamental understanding of their changes related to physiology is necessary, which can then be used to form the hypotheses such as those known from associative studies. Such hypotheses may of course be rejected, if the changes are just random findings as part of physiological changes.

\section{Specific situations}

In some specific situations, determining whether values of analyzed steroids are or are not within reference ranges can only be done with knowledge of the character of the steroid metabolome. Examples include pregnancy in particular (Adamcová et al. 2018), phase of the menstrual cycle in women, developmental phases such as puberty, menopause, andropause and aging, as well as kidney or renal function disorders, the use of various pharmaceutics, or doping. There are also completely different ratios of circulating hormones from the adrenal glands in children up to six months of age, i.e. until the fetal adrenal zone completely disappears.

\section{Age differences}

Steroid hormones play a key role in the onset of various development stages in humans. Infants up to 6 months old undergo a gradual disappearance of the fetal adrenal zone, leading to a gradual change in the adrenal steroid spectrum.

Around six years of age the adrenals begin to mature (adrenarche), which induces changes to the sensitivity of the adrenal glands to adrenocorticotropic hormone (ACTH), leading to marked changes in adrenal steroids. In children before adrenarche ACTH stimulates the secretion of cortisol, but has little influence on the secretion of adrenal androgens. During adrenarche the sensitivity of adrenal C19-steroid secretion to ACTH gradually increases selectively, while the sensitivity of cortisol to ACTH remains unchanged. The secretion profile of steroids during adrenarche is characterized by a significant reactivity of 5-unsaturated steroid intermediate products (17-hydroxypregnenolone and dehydroepiandrosterone) compared to 4-unsaturated 
steroid intermediates (17-hydroxyprogesterone and androstenedione), while the cortisol reactivity remains unchanged (Gell et al. 1998). As a result, dehydroepiandrosterone sulfate (DHEAS) becomes the most abundant C19 steroid in the blood and the main marker of adrenarche. At the beginning of adrenarche, circulating serum levels of other androgens including testosterone and its precursors are typically at the upper limit of the prepubertal range.

Even though the clinical signs of adrenarche normally are immediately followed by actual puberty, these two phenomena can be disassociated, as happens sometimes in cases of hypogonadism. Adrenarche is thus not directly connected to the pubertal maturation of the hypothalamic-pituitary-gonadal axis. Adrenal androgens influence the course of pubic and axillary hair growth, acne, and body odor. One to two years after adrenarche, the sex glands begin to mature (gonadarche), gonadotropin secretion increases, the production of sex hormones (estradiol, testosterone) increases, and external and internal genital and secondary sex characteristics develop.

Steroid hormones normally peak during the third decade and then decline, gradually in men but more rapidly in women during perimenopause. Therefore, not just the concentrations of steroid hormones but also their relative ratios change over the course of life (especially for individual steroids). For those that are most variable in time (dehydroepiandrosterone, sex hormones), data on reference ranges should be accompanied by a detailed description of age-related values.

\section{Pregnancy}

The production and function of steroid hormones during pregnancy have specific characteristics. Their synthesis and metabolism are the result of complex metabolic pathways encompassing events in the fetus, placenta, and mother. Some basic enzymes of steroidogenesis are lacking in the fetus (for instance $3 \beta$-hydroxysteroid dehydrogenase, 5-ene - 4-ene isomerase, aromatase) or in the placenta (e.g. C17-C20 lyase). The conversion of acetate to cholesterol is very active in the fetus, as is the change of pregnene to androstene and the 16-hydroxylation of DHEA, which is necessary for the production of estriol. All these transformations are lacking in the placenta, which however can metabolize cholesterol to C21-steroids, convert 5-ene to 4-ene steroids, and has a large capacity to aromatize $\mathrm{C} 19$ precursors. Together, then, the fetus and placenta can produce all necessary steroid hormones (Pasqualini and Chetrite 2016).

Steroid production in the human fetus is localized to the adrenal glands, with primitive adrenocortical cells appearing in the fourth week of gestation. Two zones can be delineated at eight weeks, a fetal zone and a definitive zone. The fetal adrenals grow very quickly, and at the end of pregnancy together weigh about $6-8 \mathrm{~g}, 80 \%$ of which make up the fetal zone that is lost several months after delivery. The definitive zone is differentiated in the well-known glomerulosa-fasciculatareticularis regions (Pasqualini and Chetrite 2016).

The production of some steroid hormones during pregnancy increases significantly (e.g. estriol increases 500-1000x compared to not pregnant). In addition to changes in steroids during pregnancy itself, various associated factors influence their levels, such as maternal age (Adamcová et al. 2018), smoking (Adamcová et al. 2017), complications of pregnancy, and treatments with glucocorticoids. These are related to the development of several childhood disorders both intrauterine and later during life (Kuijper et al. 2015). We have determined reference ranges for selected steroid hormones measured by LC-MS/MS for the $37^{\text {th }}$ week of pregnancy, the postpartum period, and in newborns (Adamcová et al. 2018).

\section{Kidney failure}

Kidney function disorders lead to alterations in most of all physiological processes in the body, including hormonal regulation. The kidneys are both the site of synthesis of some hormones and play a key role in the excretion of hormones, especially steroidal. The use of medications also plays a direct role in influencing the production of steroid hormones in patients with chronic kidney disease (CKD), including the often-prescribed angiotensin converting enzyme inhibitor (ACEI)/sartans, statins, cinacalcet, etc. (Meuwese and Carrero 2013).

Literature data on the influence of the hypothalamic-pituitary-adrenal axis on patients with CKD are inconsistent (Meuwese and Carrero 2013). Higher levels of cortisol and resistance to dexamethasone in the presence of an unchanged normal circadian rhythm have been described. In addition, higher aldosterone levels have been found, but these are difficult to evaluate since most patients with CKD use medications that influence the renin-angiotensin-aldosterone system. Patients on hemodialysis also have reduced activity of $11 \beta$-hydroxysteroid dehydrogenase. Adrenal androgens (DHEA, DHEAS) are reduced in patients with liver 
function disorders (Meuwese and Carrero 2013).

Disorders of the gonadal axis are common in CKD patients. There is a reduction due to hyperprolactinemia (from reduced prolactin clearance and increased production of the inhibitory dopaminergic activity), which is typical in these patients. In women, there is typical ovarian dysfunction with an absence of cyclical gonadotropin and estradiol secretion at the level of the hypothalamus, resulting in anovulation, fertility disorders, lowered libido, and cardiovascular problems from the lack of estrogens. In men with CKD stage 5 (renal failure), hypogonadism and all its consequences have been described in $50 \%$ of patients, along with the typically lowered testosterone. These changes worsen the anemia and resistance to erythropoietin that patients with CKD suffer from (Meuwese and Carrero 2013).

\section{The influence of pharmacotherapy}

Pharmaceutical therapy influences the levels of steroids through a variety of mechanisms. Medications interact with steroid production at all levels, change the concentrations of binding proteins, and also interfere with laboratory measurements, changing the results of determinations though possibly not their actual concentrations.

A classic example of the influence on steroid hormones by pharmacotherapy is the use of hormonal contraception. At first there is an inhibition in the secretion of ovarian steroids. Then, estrogens from the contraceptive result lead to the stimulation of protein synthesis in the liver, including proteins responsible for binding to steroid hormones. As a result, there is a higher level of total steroids (e.g. cortisol), though not a substantial change to their free fraction.

A second classic example is the external application of corticoids (by mouth, intramuscular, intravenous, intra-articular, inhalation, rectally, transdermally), which leads to an inhibition of the hypothalamic-pituitary-adrenal axis. Levels of cortisol are very low, but patients do not have a corticoid deficit and react normally to their increased usage. However, if corticoid treatments are long-term and at higher doses, they may lead to adrenal atrophy.

Another example is treatments using androgens, which improves secondary sexual characteristics and the sex life in hypogonadal men, but at the same time represses the patient's own androgen production in testicular tissues, leading to inhibited steroidogenesis in the testes. The concentration of androgens in the testes is not high enough for sperm production, resulting in infertility. Treatments with modified androgens are basically a form of male hormonal contraception. It should be noted, that this also occurs with the misuse of anabolics in doping and bodybuilding.

\section{Instrumental methods at the Institute of Endocrinology in Prague}

The Department of steroid hormones and proteofactors at the Institute of Endocrinology has long studied steroid hormones including those that are less common (Stárka and Brabencová 1959, Stárka and Brabencová 1960, Stárka et al. 1962). Because of their nanomolar concentrations in the blood, until the end of the 1960s the main steroid hormones were determined in urine. One of the first papers in the world describing determination of testosterone using a protein binding method was published by scientists from our unit (Hampl et al. 1970). Radioimmunology methods, currently in wide use for routine diagnostics, were supplemented in our laboratory by measurements using gas chromatography with mass spectrometry (GC-MS) mainly for research purposes, and we currently provide determinations for almost 100 steroids (Hill et al. 2000, Kancheva et al. 2007, Hill et al. 2010, Hill et al. 2019). We have recently introduced new methods using LC-MS/MS (Sosvorova et al. 2015a, Sosvorova et al. 2015b, Vítků et al. 2015, Vítků et al. 2016, Vítků et al. 2018).

In the following section we provide actual information on the steroids measured in our laboratory using these liquid chromatography-mass spectrometry methods. Our first LC-MS/MS method was validated for measuring dehydroepiandrosterone (DHEA), $7 \alpha$-hydroxy-dehydroepiandrosterone $\quad(7 \alpha-\mathrm{OH}-\mathrm{DHEA})$, $7 \beta$-hydroxy-dehydroepiandrosterone $\quad(7 \beta-O H-D H E A)$, 7-oxo-dehydroepiandrosterone (7-oxo-DHEA), $16 \alpha$ hydroxy-dehydroepiandrosterone (16 $\alpha$-OH-DHEA), cortisol and cortisone (Sosvorova et al. 2015a), and was then widened to include aldosterone (Sosvorova et al. $2015 \mathrm{~b}$ ). In that same year we validated a second method for estrone (E1), estradiol (E2), and estriol (E3) (V'itků et al. 2015). Then, the first method was expanded to include an additional steroid spectrum of pregnenolone, $17 \alpha$-hydroxy-pregnenolone, androstenedione, testosterone (T) and dihydrotestosterone (DHT) (Vítků et al. 2016), plus $7 \beta$-hydroxy-epiandrosterone (7 $\beta$-OH-EpiA) (Vítků et al. 2018). At this point only for research purposes, 
the method to determine cortisone, 11-deoxycortisol, corticosterone, and 11-deoxycorticosterone was developed (Šimková 2018, Šimková, unpublished data).

For these methods, LC-MS/MS was performed using an API 3200 (Sciex, Concord, Canada) triple quadrupole mass spectrometer with electrospray ionization (ESI) connected to an Eksigent ultra-high performance liquid chromatograph (UPLC) UltraLC 110 system (Redwood City, CA, USA). Chromatographic separation was carried out on various Kinetex C18 $(150 \times 3.0 \mathrm{~mm})$ columns (Phenomenex, Torrance, CA, USA) with a corresponding security guard. Measurements are done using $500 \mathrm{ml}$ of serum or plasma. Due to the very low concentrations of steroids in biological materials, derivatization is performed, which significantly increases the analytical sensitivity. Detection limits of the methods can be found in the appropriate published papers (Sosvorova et al. 2015a, Vítků et al. 2015, Vítků et al. 2016).

The main drawback to these methods is the complex and time-consuming sample preparation, including extraction with organic solvents, chemical derivatization, and several evaporation and dilution steps. The main advantage is the higher precision and ability to determine multiple steroids at once.

\section{Individual steroids}

\section{Pregnenolone}

Results from cholesterol side-chain cleavage, and represents the metabolic starting point of many steroid hormones. Most pregnenolone is secreted from the adrenal glands. The highest levels are present in the early morning, declining after 7 am until the night hours, when levels range between $1.5-3.0 \mathrm{nmol} / \mathrm{l}$. During dynamic tests of the function of the hypothalamicpituitary-adrenal axis, the secretion of pregnenolone is significantly stimulated by the ACTH test and insulininduced hypoglycemia test.

Pregnenolone and some of its derivatives are neuroactive steroids antagonizing $\mathrm{GABA}_{\mathrm{A}}$ receptor chloride channels, influencing neural activity and supporting learning and memory, decreasing depression, supporting locomotive activity and the survival of neurons (Weng and Chung 2016). Changes to levels outside reference ranges have significance for monitoring the interplay between neurosteroids and various psychiatric disorders.

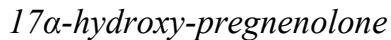

$17 \alpha$-hydroxy-pregnenolone is a precursor for other adrenal and sex steroid hormones in humans. Diurnal changes are similar to pregnenolone. Changes to levels can be supporting information in the diagnosis of adrenal enzymopathies. Higher levels are found in $3 \beta$-hydroxysteroid dehydrogenase deficits, while low or absent levels are found in deficits of $17 \alpha$-hydroxylase.

\section{Dehydroepiandrosterone (DHEA)}

In the literature, dehydroepiandrosterone is sometimes interchanged or even mis-characterized with its sulfate, from which it however differs, and in some functions even acts oppositely. In the past it was considered an insignificant intermediate product of steroid metabolism, but gradually its importance in physiology has been recognized. Dehydroepiandrosterone sulfate (DHEAS) is the main adrenal androgen, and the most abundant steroid hormone considering the amount produced. Physiological levels depend on age and sex. Concentrations of DHEAS are significantly related to age, with levels increasing during adrenarche and reaching a maximum between the ages of 20-30, after which they start to decline. DHEAS is important in some metabolic and neural functions, but its diagnostic levels are limited to evaluating adrenal status. High concentrations are found in adrenal carcinomas. In our laboratory DHEAS is determined immunoanalytically. For this reason, we do not further distinguish in this review.

As opposed to DHEAS, non-conjugated DHEA is not commonly on the list of analytes of biochemical laboratories. Some authors have indicated that it is important in the brain, where in addition to the adrenals it is produced and binds to $\mathrm{GABA}_{\mathrm{A}}$ receptor of calcium channels, thereby influencing some neural functions. It also acts on other neural pathways, and in some acts in opposite fashion than DHEAS. It crosses the blood-brain barrier (BBB) directly and more easily than DHEAS, which cross the BBB via organic anion transporting protein. DHEA concentrations profile during life are similar to those of DHEAS, but DHEA is different in having a clear diurnal profile that follows the profile of cortisol (Stárka et al. 2015). Changes during the menstrual cycle are minor, with a slight increase during the late luteal phase (Šrámková et al. 2015).

Daily amounts of total DHEA produced are much lower than DHEAS, around 3-8 $\mu \mathrm{g} / \mathrm{day}$. In women, about half is produced in the adrenal glands, and the other 
half excreted by the ovaries or produced by conversion from the sulfate in the periphery. Circulating concentrations range from 3-35 nmol/1, with significant dependence on age. In women, determining non-conjugated DHEA has limited significance for diagnosing hyperandrogenemia (Dušková et al. 2018).

\section{Hydroxy-derivatives of DHEA}

Hydroxylated metabolites, namely $7 \alpha-\mathrm{OH}-$ DHEA， 7 $\beta$-OH-DHEA，7-oxo-DHEA， 16 $\alpha$-OH-DHEA and $7 \beta$-hydroxy-epiandrosterone are compounds that play a role in the immune system and act as neuroactive steroids in the brain. The first three can regulate the cortisol/cortisone ratio in target tissues. Not significant for practical diagnosis.

\section{Androstenedione}

Androstenedione is a weak androgen. It is a direct precursor of testosterone in the gonads and estrone mainly in fatty tissues. In women, levels of circulating androstenedione change during the menstrual cycle similarly to testosterone, increasing during the periovulation period by about $25 \%$, and also displays a circadian rhythm. Slight declines in androstenedione with age have been described, but after menopause it remains the main steroid hormone of the ovaries. Fertile women have higher androstenedione levels than postmenopausal women (Stanczyk 2006). The daily production of 1.4-6.2 mg is divided in women equally between the ovaries and the adrenal glands.

Androstenedione does not have significant androgenic activity, but is a direct precursor of testosterone. For this reason, determination for the diagnosis of hyperandrogenic states in women is important. Higher levels accompanied by normal or just slightly elevated testosterone levels are common in polycystic ovarian syndrome (Dušková et al. 2018).

The testosterone/androstenedione ratio increases with increasing BMI.

Children undergoing adrenarche from 6-8 years of age have increases in DHEAS, DHEA and androstenedione. These increases possibly play a key role in learning social and cultural norms. Androstenedione plays a role in male aggressiveness and competitiveness, and its levels correlate with these characteristics during the time when testosterone levels are still minimal.

\section{Testosterone}

Testosterone is the main androgen in humans, though dihydrotestosterone is the most potent (Dušková and Pospíšilová 2011).

In men, most excretion is from the Leydig cells in the testes, though part is produced in the periphery from precursors of mainly adrenal origin. The daily production in men is about $35 \mathrm{mg}$. Secretion from the gonads is directed by LH from the pituitary, and therefore indirectly by gonadoliberin from the hypothalamus, with testosterone levels playing a negative feedback role. Testosterone influences the development of primary and secondary sexual characteristics, acts anabolically on musculature and bone, and in men underlies spermatogenesis in combination with the activity of FSH.

Testosterone levels in men are highest in the morning after waking and decline until evening before sleeping, when they again start to rise. With age the amplitude of this cycle is dampened. The dependence of age on testosterone levels is significant, resulting in partial hypogonadism with late onset if levels decline below $7 \mathrm{nmol} / \mathrm{l}$.

Determination is indicated in the differential diagnosis of testicular and ovarian endocrine function. In men, it is possible to distinguish primary and secondary testicular insufficiency (along with LH and FSH, or by using an hCG or LHRH stimulation test). During hCG or LHRH stimulation, levels of testosterone in younger and middle-aged men approximately double. Primary hypogonadism (hypergonadotropic hypogonadism) is indicated by low testosterone levels, high $\mathrm{LH}$, and negative hCG or LHRH tests. It results from, for instance, trauma to the testes, testicular torsion, orchitis (primarily mumps related), or Klinefelter syndrome. Secondary hypogonadism (hypogonadotropic hypogonadism with low testosterone and $\mathrm{LH}$ ) is caused by pathologies in the pituitary or hypothalamus. For diagnosis of hypogonadism it is recommended to measure testosterone at least three times in the morning hours, with a time delay between samplings. Using just one sampling can lead to errors due to the possible sources of interference that can influence results. Higher levels in men mainly come from doping, either using testosterone directly or stimulation through hCG (Stárka et al. 2017). Monitoring testosterone levels in men is also appropriate during substitution therapy for hypogonadism. The timing of sampling depends on the type of substitution therapy (Stárka 2007).

In women, the daily production is from 0.1-0.4 mg, half of which is converted in the periphery from precursors, and the other half produced equally in 
the adrenal glands and the ovaries. The concentration of testosterone in women changes during the menstrual cycle similarly to androstenedione, and increases during periovulation by about $25 \%$ due to increased production in the ovaries (Šrámková et al. 2015). Changes during the day have been inconsistently described in the literature; we found slightly non-significant changes in one of our studies (Rácz et al. 2015).

Increase testosterone levels in women, or rather free testosterone or the free androgen index (FAI), are confirmatory information for physicians diagnosing skinrelated signs of hyperandrogenemia. However, some women with hirsutism have been found to have androgen levels within reference ranges, so a biological marker may be more sensitive than a laboratory marker. Measuring testosterone is still important, however, for diagnosing tumor-related androgen production, when total testosterone levels can be increased 2-3x over the reference levels. In addition, the level of androgenemia is a useful marker for the diagnosis and monitoring the course of androgenizing disorders (Dušková et al. 2018).

\section{Estrone}

Estrone is a relatively weak estrogen produced from androstenedione, about half in the ovaries, $5 \%$ in the adrenals, and the rest in the periphery. The ratio between estrone and estradiol increases with age. In women, levels of estrone change both during the menstrual cycle and with age. In men, estrone is produced in the testes and partially the adrenals, with no major daily, cyclical, or age-related changes.

\section{Estradiol}

Estradiol is the most potent estrogen and together with progesterone directs female reproductive development. It is produced in ovarian follicles of sexually mature women, mainly during the period around ovulation, during pregnancy, and in small amounts is also produced in the adrenal glands. Its production is directed by pituitary $\mathrm{FSH}$, and therefore indirectly by gonadoliberin from the hypothalamus. Circulating estradiol exhibits negative feedback on estradiol production. On the other hand, higher estradiol concentrations during ovulary follicle maturation have a positive feedback on the increase of LH.

Higher concentrations of estradiol occur in tumors and ovarian cysts producing hormones. Increased estradiol levels before puberty lead to pre-term puberty, and in sexually mature individuals to anovulatory cycles and bleeding disorders.

Lower levels can occur in ovarian insufficiency or in disorders of the hypothalamic-pituitary-ovarian axis, and are associated with cycle dysfunctions and even amenorrhea. In polycystic ovarian syndrome the ovarian production of estradiol is connected with increased androgen production, which in the periphery can be aromatized to estrone, so the estradiol/estrone ratio is altered.

In men, a small amount of estradiol is produced in the testes and adrenal glands. Tumors of these organs can lead to increased levels of estradiol in men, resulting in feminization. This can also result from major liver disorders due to the reduced degradation of estrogen, with subsequent feminization and appearance of gynecomastia.

In addition to reproductive functions, estradiol plays a key role in the metabolism of bone bass, muscle and fatty tissues. During fetal development it is responsible for gender differentiation of the brain, with higher amounts influencing the development of the male brain and lower amounts the female brain (McCarthy 2008).

\section{Estriol}

Estriol is the dominant estrogen in pregnancy. Estriol is produced from the hydroxylation of estradiol or estrone, and after conjugation is the most abundant form in which estrogens are excreted from the body. During pregnancy, estriol is produced in the placenta from precursors, especially DHEA, and from the adrenal glands of both the fetus $(90 \%)$ and the mother. From the amniotic fluid it travels transplacentally to the mother's circulation and is excreted in the urine in conjugated form. Measuring estriol in maternal blood can help diagnose the status of the fetal-placental unit. Because values vary over a wide range, they are most reliable after the $28^{\text {th }}$ week of pregnancy. Declines in estriol values signal fetal distress, for instance anoxia.

\section{Cortisol}

Cortisol (in pharmacology, manufactured cortisol is termed hydrocortisone) is the most potent glucocorticoid hormone in humans produced in the adrenal glands. Its secretion is stimulated by ACTH and exhibits feedback inhibition. Cortisol plays a main role in the reaction of the organism to various stresses (stress, infectious diseases, large loads on the body, long-term lack of food), acting on the metabolism with a catabolic 
effect. However, in the liver it has an anabolic effect and increases gluconeogenesis. Cortisol is involved in the conversion of all basic nutrients. It has a significant circadian rhythm with a maximum in the morning and minimum in the evening.

Higher values are seen in Cushing's syndrome/disease, while lower values can result from adrenal insufficiency. A lack of a diurnal rhythm is one symptoms of Cushing's syndrome/disease. Cortisol in saliva is proportional to free cortisol in the urine, and can be used to diagnose hypercortisolemia. Its levels do not depend on the salivary intensity. Increased excretion of free cortisol in the urine is a sign of Cushing's syndrome/disease. However, to confirm this diagnosis cortisol determination alone is not enough, and a suppressive test with dexamethasone is needed. Lower levels of cortisol can result from adrenal insufficiency, but a single measurement is also not enough for diagnosis, and a Synacthen test is needed (Kosák et al. 2017). As in adrenal hyperfunction, a definitive diagnosis of hypofunction should distinguish at which level of the hypothalamic-pituitary-adrenal axis the defect is present.

\section{Cortisone}

Cortisone is a much weaker glucocorticoid than cortisol regarding effects on target tissues. Its conversion in the tissues is performed by the enzyme
$11 \beta$-hydroxysteroid dehydrogenase, which determine the resulting glucocorticoid activity in those tissues. Cortisone determination has no particular diagnostic relevance.

\section{Conclusions}

Steroid hormones are determined in most laboratories using immunoanalytic methods. Recently, measurements using gas or liquid chromatography combined with mass spectrometry have become more common for routine analyses. Our laboratory has a long history of analyzing a wide spectrum of steroid hormones, for both routine clinical use and for research purposes. We focus not just on physiological relationships, but also the connections and associations with various diseases. The aim of this work is to help provide orientation in the labyrinth of data on steroid hormones and their metabolites.

\section{Conflict of Interest}

There is no conflict of interest.

\section{Acknowledgements}

This work was supported by a grant from the Health Ministry of the Czech Republic (MZČR - RVO („Endokrinologický ústav - EÚ00023761“).

\section{References}

ADAMCOVÁ K, KOLÁTOROVÁ L, JANDÍKOVÁ H, CHLUPÁČOVÁ T, ŠMÍDOVÁ M, PAŘÍZEK A, STÁRKA L, DUŠKOVÁ M: Changes to fetal steroidogenesis caused by maternal smoking. Physiol Res 66 (Suppl 3): S375-S386, 2017. https://doi.org/10.33549/physiolres.933728

ADAMCOVÁ K, KOLÁTOROVÁ L, ŠKODOVÁ T, ŠIMKOVÁ M, PAŘÍZEK A, STÁRKA L, DUŠKOVÁ M: Steroid hormone levels in the peripartum period - differences caused by fetal sex and delivery type. Physiol Res 67 (Suppl 3): S489-S497, 2018. https://doi.org/10.33549/physiolres.934019

DUŠKOVÁ M, POSPÍŠILOVÁ H: The role of non-aromatizable testosterone metabolite in metabolic pathways. Physiol Res 60: 253-261, 2011. https://doi.org/10.33549/physiolres.932080

DUŠKOVÁ M, KOLÁTOROVÁ L, STÁRKA L: Androgens in women - critical evaluation of the methods for their determination in diagnostics of endocrine disorders. Physiol Res 67 (Suppl 3): S379-S390, 2018. https://doi.org/10.33549/physiolres.933964

EISENHOFER G, PEITZSCH M, KADEN D, LANGTON K, PAMPORAKI C, MASJKUR J, TSATSARONIS G, MANGELIS A, WILLIAMS TA, REINCKE M, LENDERS JWM, BORNSTEIN SR: Reference intervals for plasma concentrations of adrenal steroids measured by LC-MS/MS: impact of gender, age, oral contraceptives, body mass index and blood pressure status. Clin Chim Acta 470: 115-124, 2017. https://doi.org/10.1016/j.cca.2017.05.002

GELL JS, CARR BR, SASANO H, ATKINS B, MARGRAF L, MASON JI, RAINEY WE: Adrenarche results from development of a 3beta-hydroxysteroid dehydrogenase-deficient adrenal reticularis. J Clin Endocrinol Metab 83: 3695-3701, 1998. https://doi.org/10.1210/jc.83.10.3695 
GOLDMAN AL, BHASIN S, WU FCW, KRISHNA M, MATSUMOTO AM, JASUJA R: A reappraisal of testosterone's binding in circulation: physiological and clinical implications. Endocr Rev 38: 302-324, 2017. https://doi.org/10.1210/er.2017-00025

HAMPL R, RABOCH J, STÁRKA L: Determination of testosterone using the protein-binding method and its level in male plasma. (In Czech) Cas Lek Cesk 109: 616-619, 1970.

HILL M, PARÍZEK A, BICÍKOVÁ M, HAVLÍKOVÁ H, KLAK J, FAIT T, CIBULA D, HAMPL R, CEGAN A, SULCOVÁ J, STÁRKA L: Neuroactive steroids, their precursors, and polar conjugates during parturition and postpartum in maternal and umbilical blood: 1. Identification and simultaneous determination of pregnanolone isomers. J Steroid Biochem Mol Biol 75: 237-244, 2000. https://doi.org/10.1016/S0960-0760(00)00192-8

HILL M, PAŘÍZEK A, KANCHEVA R, DUŠKOVÁ M, VELÍKOVÁ M, KŘÍŽ L, KLÍMKOVÁ M, PAŠKOVÁ A, ŽIŽKA Z, MATUCHA P, MELOUN M, STÁRKA L: Steroid metabolome in plasma from the umbilical artery, umbilical vein, maternal cubital vein and in amniotic fluid in normal and preterm labor. J Steroid Biochem Mol Biol 121: 594-610, 2010. https://doi.org/10.1016/j.jsbmb.2009.10.012

HILL M, HÁNA V JR, VELÍKOVÁ M, PAŘíZEK A, KOLÁTOROVÁ L, VÍTKU゚ J, ŠKODOVÁ T, ŠIMKOVÁ M, ŠIMJÁK P, KANCHEVA R, KOUCKÝ M, KOKRDOVÁ Z, ADAMCOVÁ K, ČERNÝ A, HÁJEK Z, DUŠKOVÁ M, BULANT J, STÁRKA L: A method for determination of one hundred endogenous steroids in human serum by gas chromatography-tandem mass spectrometry. Physiol Res 68: 179-207, 2019. https://doi.org/10.33549/physiolres.934124

KANCHEVA L, HILL M, VCELÁKOVÁ H, VRBÍKOVÁ J, PELIKÁNOVÁ T, STÁRKA L: The identification and simultaneous quantification of neuroactive androstane steroids and their polar conjugates in the serum of adult men, using gas chromatography-mass spectrometry. Steroids 72: 792-801, 2007. https://doi.org/10.1016/j.steroids.2007.06.006

KOSÁK M, DUŠKOVÁ M, STÁRKA L, JANDÍKOVÁ H, POSPÍŠILOVÁ H, ŠRÁMKOVÁ M, HÁNA V, KRŠEK M, SPRINGER D, ŠIMUNKOVÁ K: Can the gold standard be beaten? How reliable are various modifications of the Synacthen test compared to the insulin tolerance test. Physiol Res 66 (Suppl 3): S387-S395, 2017. https://doi.org/10.33549/physiolres.933729

KUIJPER EA, TWISK JW, KORSEN T, CAANEN MR, KUSHNIR MM, ROCKWOOD AL, MEIKLE AW, HOMPES PG, WIT JM, LAMBALK CB: Mid-pregnancy, perinatal, and neonatal reproductive endocrinology: a prospective cohort study in twins and singleton control subjects. Fertil Steril 104: 1527-1534, 2015. https://doi.org/10.1016/j.fertnstert.2015.08.016

MCCARTHY M: Estradiol and developing brain. Physiol Rev 88: 91-134, 2008. https://doi.org/10.1152/physrev.00010.2007

MEUWESE CL, CARRERO JJ: Chronic kidney disease and hypothalamic-pituitary axis dysfunction: the chicken or the egg? Arch Med Res 44: 591-600, 2013. https://doi.org/10.1016/j.arcmed.2013.10.009

OETTEL M, MUKHOPADHYAY AK: Progesterone: the forgotten hormone in men? Aging Male 7: 236-257, 2004. https://doi.org/10.1080/13685530400004199

PASQUALINI JR, CHETRITE GS: The formation and transformation of hormones in maternal, placental and fetal compartments: biological implications. Horm Mol Biol Clin Investig 27: 11-28, 2016. https://doi.org/10.1515/hmbci-2016-0036

RACEK J, EISELT J, FRIEDECKÝ B, HOLEČEK V, NEKULOVÁ M, PITTROVÁ H, RUŠAVÝ Z, SENFT V, ŠAVLOVÁ M, TĚŠÍNSKÝ P, VERNER M: Clinical Biochemistry. (In Czech) Second edition. Galén, Prague, $2006,329 \mathrm{p}$.

RÁCZ B, DUŠKOVÁ M, VONDRA K, ŠRÁMKOVÁ M, STÁRKA L: Daily profiles of steroid hormones and their metabolites related to food intake. Physiol Res 64 (Suppl 2): S219-S226, 2015. https://doi.org/10.33549/physiolres.933070

SOSVOROVA L, VÍTKŮ J, CHLUPACOVA T, MOHAPL M, HAMPL R: Determination of seven selected neuro- and immunomodulatory steroids in human cerebrospinal fluid and plasma using LC-MS/MS. Steroids 98: 1-8, 2015a. https://doi.org/10.1016/j.steroids.2015.01.019

SOSVOROVA L, HILL M, MOHAPL M, VÍTKU゚ J, HAMPL R: Steroid hormones in prediction of normal pressure hydrocephalus. J Steroid Biochem Mol Biol 152: 124-132, 2015b. https://doi.org/10.1016/j.jsbmb.2015.05.004 
STANCZYK FZ: Measurement of androgens in women. Semin Reprod Med 24: 78-85, 2006. https://doi.org/10.1055/s$\underline{2006-939566}$

STARKA L, BRABENCOVA H: Fractionation of urinary 17-ketosteroids with paper chromatography. (In Czech) Cas Lek Cesk 98: 1229-1232, 1959.

STARKA L, BRABENCOVA H: Polarographic determination of pregnane-3alpha,17alpha,20alpha-triol and other acetaldehydogenic urinary steroids. (In German) Clin Chim Acta 5: 423-430, 1960. https://doi.org/10.1016/0009-8981(60)90149-2

STARKA L, SULCOVA J, SILINK K: Urinary excretion of 7-hydroxydehydroepiandrosterone sulfate. Clin Chim Acta 7: 309-316, 1962. https://doi.org/10.1016/0009-8981(62)90029-3

STÁRKA L, RÁCZ B, ŠRÁMKOVÁ M, HILL M, DUŠKOVÁ M: Daily profiles of dehydroepiandrosterone and its hydroxylated metabolites with respect to food intake. Prague Med Rep 116: 40-48, 2015. https://doi.org/10.14712/23362936.2015.44

SWERDLOFF RS, DUDLEY RE, PAGE ST, WANG C, SALAMEH WA: Dihydrotestosterone: biochemistry, physiology, and clinical implications of elevated blood levels. Endocr Rev 38: 220-254, 2017. https://doi.org/10.1210/er.2016-1067

ŠIMKOVÁ M: Development of LC-MS/MS method for analysis of steroids for diagnostics. (In Czech) 2018. https://repozitar.vscht.cz/theses/24385/

ŠRÁMKOVÁ M, DUŠKOVÁ M, VÍTKU゚ J, VČELÁK J, MATUCHA P, BRADNOVÁ O, DE CORDEIRO J, STÁRKA L: Levels of adipokines and some steroids during the menstrual cycle. Physiol Res 64 (Suppl 2): S147-S154, 2015. https://doi.org/10.33549/physiolres.933116

VERMEULEN A, VERDOCK L, KAUFMAN JM: A critical evaluation of simple methods for the estimation of free testosterone in serum. J Clin Endocrinol Metab 84: 3666-3672, 1999. https://doi.org/10.1210/jcem.84.10.6079

VÍTKŮ J, CHLUPACOVA T, SOSVOROVA L, HAMPL R, HILL M, HERACEK J, BICIKOVA M, STARKA L: Development and validation of LC-MS/MS method for quantification of bisphenol A and estrogens in human plasma and seminal fluid. Talanta 140: 62-67, 2015. https://doi.org/10.1016/j.talanta.2015.03.013

VÍTKŮ J, HERACEK J, SOSVOROVA L, HAMPL R, CHLUPACOVA T, HILL M, SOBOTKA V, BICIKOVA M, STARKA L: Associations of bisphenol A and polychlorinated biphenyls with spermatogenesis and steroidogenesis in two biological fluids from men at tending an infertility clinic. Environ Int 89-90: 166-173, 2016. https://doi.org/10.1016/j.envint.2016.01.021

VÍTKŮ J, KOLATOROVA L, RICCO C, FERROUD C, HENNEBERT O, SKODOVA T, HERACEK J, STARKA L: The quantitation of $7 \beta$-hydroxy-epiandrosterone in the plasma and seminal plasma of men with different degrees of fertility. Physiol Res 67 (Suppl 3): S511-S519, 2018. https://doi.org/10.33549/physiolres.933963

WENG JH, CHUNG BC: Non genomic actions of neurosteroid pregnenolone and its metabolites. Steroids 111: 54-59, 2016. https://doi.org/10.1016/j.steroids.2016.01.017 